\title{
Assessment of Quality of Life among Beta-Thalassemia Major Patients Attending the Hematology Outpatient Clinics at Cairo University Hospital
}

\author{
Mona Hamdy ${ }^{1}$, Iman Hassan Draz ${ }^{1}$, Inas Talaat El Sayed ${ }^{2}$, Azza Ali Fahmy Ayad ${ }^{3}$, Marwa Rashad Salemd ${ }^{4 *}$ \\ ${ }^{1}$ Department of Pediatrics, Faculty of Medicine, Cairo University, Giza, Egypt; ${ }^{2}$ Department of Family Medicine, Faculty of \\ Medicine, Cairo University, Giza, Egypt; ${ }^{3}$ Department of Pediatrics, Children Cancer Hospital Egypt 57357, Cairo, Egypt; \\ ${ }^{4}$ Department of Public Health and Community Medicine, Faculty of Medicine, Cairo University, Giza, Egypt
}

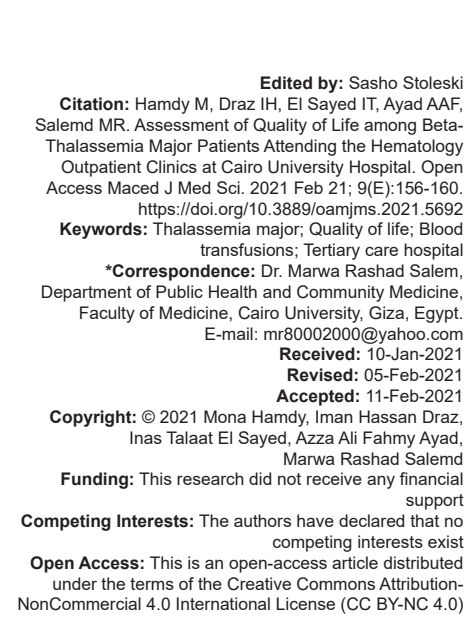

\begin{abstract}
AIM: This paper aimed at assessing the quality of life (QoL) among beta ( $\beta$ )-thalassemia major patients using the short-form-36questionnaire (SF-36) and determining the factors associated with it.

METHODS: A cross-sectional study was conducted among $\beta$-thalassemia major patients who were attending the hematology outpatient clinic at Cairo University Hospital using the consecutive sampling technique. Data were collected between October 2016 and March 2017. The QoL was assessed for patients aged $\geq 17$ years. During the study period, a total number of 112 patients were included for participation.

RESULTS: The mean age of the studied group was $18.32 \pm 1.33$ years. Most of the included patients $(93.63 \%)$ had 1 monthly blood transfusion. The mean total score of SF-36 was $44.90 \pm 7.54$. Among the QoL domains of the studied patients, the "general health perception" domain was the most affected one with a mean score of (add the value of the score here), while the "vitality" domain was the least affected one. No statistically significant difference was reported between males and females regarding different QoL domains except for the "vitality" domain which mean score was significantly higher in males compared to females $(p=0.05)$. The age at onset of the disease and at first blood transfusion was the most documented factors to be positively correlated with the QoL among the studied patients.

CONCLUSION: This study revealed that the QoL in thalassemia major patients is compromised. QoL assessment should be performed for all thalassemia patients to determine and implement the necessary interventions that focus on the affected domains.
\end{abstract}

\section{Introduction}

Beta $(\beta)$-thalassemia is considered as a major public health problem in the Mediterranean region and Southeast Asia [1], especially in the Middle East and North Africa where a high percentage of thalassemia major patients and carriers has been reported. This is attributed to consanguineous marriage in these areas [2]. In Egypt, about $4.5 \%$ of the population are $\beta$-thalassemia carriers [3].

Thalassemia major patients undergo a rigorous remedy regimen that starts in infancy including frequent blood transfusions and iron chelating therapy [4]. At present, patients with this disease have longer life expectancies because of the advancements in its treatment [5]. However, these longer life expectancies are associated with some challenges including frequent blood transfusions, daily use of iron chelators, cardiac and hepatic problems as well as splenectomy; all these challenges affect the patient's quality of life (QoL) by affecting his mental, physical, social, and educational functions [6].
Despite the recent evidence demonstrating the importance of improved QoL in treating chronic diseases such as thalassemia and controlling their symptoms [7], the QoL of patients with thalassemia major have been assessed in very few studies in Egypt [8]. The authorities providing services to patients with this disease should be acquainted with its physical and psychological consequences to create a better living environment for them [6]. Therefore, the current study aimed at assessing the health-related QoL (HRQoL) among $\beta$-thalassemia major patients in the hematology clinic of the Children Hospital, Cairo University during a period of 6 months using the short-form-36 questionnaire (SF36) and determining the factors associated with it.

\section{Methods}

\section{Study setting and design}

The current study is an analytical crosssectional study involving $\beta$-thalassemia major patients 
aged $>17$ years who were attending the hematology outpatient clinics at the Children University Hospital, Cairo University. The patients involved in the study were chosen from the waiting area and interviewed in one of the clinics.

\section{Sample size and sampling technique}

A consecutive sample of adolescents and adults with $\beta$-thalassemia major who attended the hematology outpatient clinics for treatment and blood transfusion at the participating hospital during the study period and was eligible to be surveyed was recruited to participate in the study. They have been registered there since diagnosis and follow-up for life. The number of patients involved in this study is 112. The subjects selected were patients with confirmed $\beta$-thalassemia major, aged $>17$ years, and willing to participate in the study. Patients with impaired cognitive function or severe clinical condition that limit their ability to participate in the study were excluded from the study. Participants recruitment started in January 2019 and continued for 6 months.

\section{Data collection tools}

\section{major patients}

SF-36 during the interview with thalassemia

The Arabic version of SF-36 tool was used to assess HRQoL outcomes. SF-36 is a generic questionnaire that measures two major subjective health concepts: Physical and mental health. The form covers 36 items yielding a profile of eight concepts: Physical functioning, role limitations due to physical problems, bodily pain, general health perception, vitality, social functioning, role limitations due to emotional problems, and mental health. The reliability and validity of SF-36 are documented in all available language versions [9], [10], [11], [12]

In this study, the responses of participants to each SF-36 item were scored and summed according to a standardized scoring protocol and expressed as a score on a $0-100$ scale for each of the eight health concepts. Higher scores point out to better selfperceived health or a higher level of function [13].

\section{Patients' files}

A separate sheet was generated to collect the required data from each patient's medical record: Age, gender, age at onset of the disease, age at the first blood transfusion, the frequency of blood transfusion, history of splenectomy, and complications (e.g., diabetes mellitus, and cardiomyopathy). Laboratory data (within the 3 months before the study) were collected from the patients' files including serum ferritin (SF), alanine transaminase $(A L T)$, aspartate transaminase (AST), pre-transfusion hemoglobin $(\mathrm{Hb})$, andiron chelation treatment including age at the start of chelation, type of chelation, and compliance of the patient to it.

\section{Ethical considerations}

The Medical Committee in the Pediatric Department of Faculty of Medicine, Cairo University revised and approved the study protocol. Informed consent was obtained from each participant after the proper orientation of the study's impact and objectives as well as data confidentiality. For the participants under 18 years old, assent and parental consent were obtained. Interviewing patients individually were considered to keep their privacy. All procedures for data collection were treated with confidentiality according to Helsinki Declarations of biomedical ethics [14].

\section{Data management and statistical analysis}

The data were coded, entered, and analyzed using the statistical package SPSS version 21. For categorical data, frequency and percentage were used for reporting and Chi-square was used for comparison. For continuous data, mean and standard deviation were used for reporting the quantitative normally distributed data, while median and interquartile range were used for reporting non-normally distributed quantitative data. Mann-Whitney test was used to compare the differences between two independent groups. Spearman's rho non-parametric correlation was used to test the association between quantitative variables. $p \leq 0.05$ was considered as statistically significant.

\section{Results}

A total number of $112 \beta$-thalassemia major patients were enrolled in the present study during its period. As revealed in Table 1, more than half of the patients $(56.2 \%)$ were males. Most patients $(94.6 \%)$ were receiving once-per-month blood transfusion. All of the enrolled patients were receiving iron chelation therapy; about half of them (49.1\%) were on deferiprone. Moreover, most of the studied patients (98.2\%) reported that they underwent splenectomy.

As demonstrated in Table 2, the mean age at onset of the disease was 6.71 months and the mean baseline $\mathrm{Hb}$ before blood transfusion was $7.07 \mathrm{mg} / \mathrm{ml}$, while the median SF level was 660.00 (541.25-784.50) $\mathrm{ng} / \mathrm{dl}$.

As shown in Table 3, the mean total QoL score of the studied patients was $44.90 \pm 7.54$. According to severity, the "general health perception" domain was the most severely affected domain in the patients' 
Table 1: Demographic and clinical characteristics of the enrolled $\beta$-thalassemia major patients

\begin{tabular}{|c|c|}
\hline Characteristics & $(n=112)$ \\
\hline Age in years (Mean $\pm S D)$ & $18.32 \pm 1.33$ \\
\hline \multicolumn{2}{|l|}{$\operatorname{Sex}(n \%)$} \\
\hline Male & $63(56.2)$ \\
\hline \multicolumn{2}{|c|}{ Frequency of blood transfusion ( $\mathrm{n} \%$ ) } \\
\hline Every 1 month & $106(94.6)$ \\
\hline Every 3 weeks & $6(5.4)$ \\
\hline \multicolumn{2}{|l|}{ Iron chelator $(\mathrm{n} \%)$} \\
\hline DFP (deferiprone) & 55 (49.1) \\
\hline DFO (deferroxamine) & 49 (43.8) \\
\hline DFX (deferasirox) & $8(7.1)$ \\
\hline \multicolumn{2}{|c|}{ Compliance to iron chelator ( $\mathrm{n} \%$ ) } \\
\hline Yes & $74(66.1)$ \\
\hline No & $38(33.9)$ \\
\hline \multicolumn{2}{|c|}{ Complications of the disease (more than one answer) $(n \%) n=41$} \\
\hline Hepatomegaly & $26(63.4)$ \\
\hline Cardiomyopathy & $9(22.0)$ \\
\hline Diabetes Mellitus & $6(14.6)$ \\
\hline \multicolumn{2}{|l|}{ Splenectomy ( $\mathrm{n} \%$ ) } \\
\hline Yes & $110(98.2)$ \\
\hline No & $2(1.8)$ \\
\hline
\end{tabular}

QoL, while the "vitality" was the least affected one. As revealed from Figure 1, no statistically significant difference was reported between males and females

Table 2: Medical history and laboratory investigations of the enrolled $\beta$-thalassemia major patients

\begin{tabular}{ll}
\hline Item & Mean $\pm \mathrm{SD}(\mathrm{n}=112)$ \\
\hline Age at onset of the disease (month) & $6.71 \pm 1.54$ \\
${\text { Age of } 1^{\text {st }} \text { blood transfusion (month) }}^{\text {Age of splenectomy (years) }}$ & $7.06 \pm 1.61$ \\
Age of start chelation (years) $_{\text {SF level (ng/dl) }}{ }^{a}$ & $7.61 \pm 1.12$ \\
Hb before blood transfusion (mg/dl) & $2.86 \pm 0.59$ \\
AST (U/L) & $1654.63 \pm 943.33$ \\
ALT (U/L) & $7.07 \pm 0.20$ \\
\hline SF: Serum ferritin; AST: Aspartate transaminase; ALT: Alanine transaminase; Hb: Hemoglobin; ${ }^{a}$ The \\
reference range for ferritin level is $7.0-140.0 \mathrm{ng} / \mathrm{ml}$, AST (10-40 U/L), ALT (7-56 U/L).
\end{tabular}

regarding different QoL domains except for the "vitality" domain where the mean score was significantly higher in males than in females $(p=0.05)$.

Table 3: HRQoL of the enrolled patients with $\beta$-thalassemia major according to SF-36 scoring form

\begin{tabular}{ll}
\hline Subscales & Mean $\pm \mathrm{SD}(\mathrm{n}=112)$ \\
\hline Physical functioning & $51.16 \pm 18.56$ \\
Physical role limitation & $48.66 \pm 27.02$ \\
Bodily pain & $33.82 \pm 16.57$ \\
General health perception & $27.54 \pm 10.00$ \\
Vitality & $51.56 \pm 9.68$ \\
Mental health & $49.96 \pm 9.42$ \\
Social functioning & $46.09 \pm 17.29$ \\
Emotional role limitation & $41.07 \pm 30.67$ \\
Total SF-36 & $44.90 \pm 7.54$ \\
\hline HRQoL: Health-related quality of life; SF-36: Short-form-36 questionnaire.
\end{tabular}

Table 5 illustrates a statistically significant weak positive correlation between the age at onset of the disease, "physical functioning" domain $(p=0.02)$, and the "bodily pain" domain $(p=0.019)$ with the total SF-36

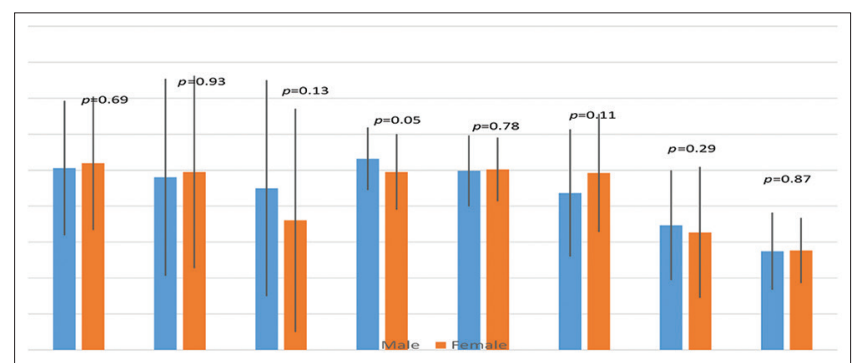

Figure 1: Comparison between mean scores for SF-36 domains in male and female patients

score $(p=0.001)$ in addition to another significant weak positive correlation between the age at splenectomy
Table 4: Correlation between quality subscales SF-36 and different demographic, clinical, and laboratory investigations of the studied thalassemia patients

\begin{tabular}{|c|c|c|c|c|}
\hline Characteristics & $\begin{array}{l}\text { Physical } \\
\text { functioning }\end{array}$ & $\begin{array}{l}\text { Physical role } \\
\text { limitation }\end{array}$ & $\begin{array}{l}\text { Emotional role } \\
\text { limitation }\end{array}$ & Vitality \\
\hline \multicolumn{5}{|l|}{ Age } \\
\hline$r^{* *}$ & -0.028 & 0.047 & -0.129 & -0.096 \\
\hline $\mathrm{p}$-value & 0.767 & 0.623 & 0.176 & 0.312 \\
\hline \multicolumn{5}{|l|}{ Age of onset } \\
\hline$r^{\star *}$ & 0.209 & 0.075 & 0.158 & 0.123 \\
\hline $\mathrm{p}$-value & 0.027 & 0.429 & 0.096 & 0.196 \\
\hline \multicolumn{5}{|c|}{ Age of 1st transfusion } \\
\hline$r^{\star *}$ & 0.173 & 0.121 & 0.111 & 0.020 \\
\hline$p$-value & 0.068 & 0.203 & 0.246 & 0.832 \\
\hline \multicolumn{5}{|c|}{ Age of splenectomy } \\
\hline$r^{\star *}$ & -0.142 & 0.130 & 0.276 & -0.007 \\
\hline$p$-value & 0.139 & 0.175 & 0.004 & 0.943 \\
\hline \multicolumn{5}{|l|}{ AST } \\
\hline$r^{\star *}$ & 0.096 & -0.014 & -0.029 & 0.109 \\
\hline $\mathrm{p}$-value & 0.316 & 0.887 & 0.759 & 0.251 \\
\hline
\end{tabular}

and the "emotional role limitation" domain $(p=0.004)$. The statistical analysis also revealed a statistically significant weak negative correlation between AST level and the "mental health" domain $(p=0.042)$. A weak positive correlation between the age at first blood transfusion and total score of QoL was also revealed. Moreover, it was found that the "physical role limitation," "social function," and "vitality" domains do not correlate with ALT or SF level of the studied thalassemia patients (Table 5).

Table 5: Correlation between quality subscales SF 36 and different demographic, clinical, and laboratory investigations of the studied thalassemia patients

\begin{tabular}{|c|c|c|c|c|}
\hline Characteristics & Mental health & Pain & General health & Total SF 36 \\
\hline \multicolumn{5}{|l|}{ Age, AST, ALT } \\
\hline$r^{\star \star}$ & 0.024 & -0.103 & -0.214 & -0.170 \\
\hline$p$-value & 0.803 & 0.280 & 0.024 & 0.073 \\
\hline \multicolumn{5}{|l|}{ Age of onset } \\
\hline$r^{* *}$ & -0.109 & 0.222 & 0.158 & 0.297 \\
\hline $\mathrm{p}$-value & 0.253 & 0.019 & 0.097 & 0.001 \\
\hline \multicolumn{5}{|c|}{ Age of $1^{\text {st }}$ transfusion } \\
\hline $\mathrm{r}^{* *}$ & -0.056 & 0.118 & 0.107 & 0.263 \\
\hline $\mathrm{p}$-value & 0.558 & 0.216 & 0.260 & 0.005 \\
\hline \multicolumn{5}{|c|}{ Age of splenectomy } \\
\hline$r^{* *}$ & 0.020 & -0.034 & 0.003 & 0.026 \\
\hline $\mathrm{p}$-value & 0.838 & 0.727 & 0.976 & 0.787 \\
\hline \multicolumn{5}{|l|}{ AST } \\
\hline$r^{\star *}$ & -0.193 & -0.100 & -0.133 & 0.000 \\
\hline $\mathrm{p}$-value & 0.042 & 0.293 & 0.162 & 0.998 \\
\hline
\end{tabular}

questionnaire; ALT: Alanine transaminase.

\section{Discussion}

The current study revealed a low mean total QoL score $(44.90 \pm 7.54)$ among the enrolled $\beta$-thalassemia major patients. This may be attributed to the challenge of having a normal daily life with the procedures of treating a chronic disease like thalassemia including frequent hospital visits for transfusions and iron chelation therapy complications such as hepatitis, cardiomyopathy, and diabetes. It may be also attributed to patients' non-compliance to iron chelators as reported by one-third of the study participants. It is recognized that the presence of comorbidities among thalassemia children is a strong predictor of poor physical health 
and low total QoL score [15]. The total QoL in this study is lower than the scores reported in other studies conducted among thalassemia major patients [16], [17]; this could be attributed two reasons. The first reason is that we do not have definite definition or measurements for QoL; it is a social concept affected by the cultural and contextual factors [18]. The second one is that the study was performed in a university hospital offering free services; therefore, its attendees are from the low socio-economic sector of the population and the financial status of patients reflects their QoL [19].

In the current study, the highest mean score was for the "vitality" domain followed by "physical functioning." This could be explained by the regular blood transfusion among the surveyed patients which can improve the physical health status. This mean score is less than those revealed from other studies Baraz et al.,2016 [1]; Jameel et al., 2016 [7] which may be attributed to the difference between studies regarding the age at onset of the disease, compliance to treatment, and frequency of blood transfusion.

The lowest mean score among QoL domains was for "general health perception." The possible explanation for this finding is that all the study participants were transfusion dependent and experienced symptoms of anemia such as fatigue and weakness before blood transfusion because blood transfusion is given only at low $\mathrm{Hb}$ levels due to scarcity of blood supply in Egypt. Hence, this might affect the general health perception negatively.

The results also demonstrated a low mean score in the "mental health" domain. Khani and Ansari study revealed the same results Khani et al. [1]; Ansari et al. [19]; this may be attributed to the emotional exhaustion the patients experience because of the disease treatment procedures as the blood transfusion and chelation therapy require frequent invasive measures and hospital visits El Dakhakhny et al. [20].

There was no statistically significant difference between males and females regarding different QoL domains except for the "vitality" domain in which its mean score was significantly higher in males than females. On the contrary, Baraz et al. [1], Emadi Dehaghi et al. [17], and Hassan et al. [18] found no significant differences between males and females regarding all QoL domains.

In consistent with a study conducted by Caocci et al. [21], among the Middle Eastern children with $\beta$-thalassemia a significant positive correlation between the age at onset of the disease, "physical functioning" domain, and total QoL score was revealed. This could be explained by the fact that younger patients could have fewer experiences in dealing with their illness and may have trouble understanding the disease they suffer from, while older children could have more knowledge about thalassemia and would be able to understand the support from their parents, caregivers, or peers to allow them to cope better with the disease Mikelli and Tsiantis [22]. In contrast to the current study findings, Adib-Hajbaghery et al. [16] reported that there was no significant correlation between the age at onset of the disease and QoL scores. This contradiction might be explained by the different scales used to assess the QoL such as sample size, age group, geographical regions, race, culture, and health-care quality.

A significant weak positive correlation between the age at splenectomy and "emotional role limitation" domain was revealed. This might be due to the size and shape of the scaras well as the patients' sense of embarrassment because of their skin appearance.

Even though the current proof demonstrates the severe mortality and morbidity that might be caused by long-term iron overload [2], SF level did not show any association with the QoL among thalassemia patients in the current study. The possible explanation for this finding is that the SF level is not an accurate measure of iron burden. Recent methods for detecting iron overload as magnetic resonance imaging are not accessible to all patients in our community. Moreover, baseline $\mathrm{Hb}$ levels did not show any association with the QoL in thalassemia patients appropriate anemia control for the almost acceptable QoL where more than half of thalassemia patients had $\mathrm{Hb}$ level greater than $7 \mathrm{~g} / \mathrm{dL}$ might be the explanation for this finding. Transfusion practice in Egypt mainly depends on the availability of blood units where transfusion is usually given at $\mathrm{Hb}$ level of $7 \mathrm{~g} / \mathrm{dl}$ or less.

The age at first transfusion before 4 years was found to be significantly associated with HRQoL with low total summary scores [23]. In the current study, a significant positive correlation was revealed between the age of onset of blood transfusion and QoL. This agrees with a previous study conducted by Saha et al., [24].

Restricting the sample of patients to only attendants of a hematology outpatient clinic in one hospital may have limited these findings for convenience. Additional studies are needed to develop a full picture of QoL among thalassemia patients. There is a wide room for further progress in determining the QoL among thalassemia patients.

\section{Conclusion}

The low mean total QoL score noted portrays the burden of thalassemia disease in its patients despite the effective management of their treatment. The age at onset of the disease and age at first blood transfusion are the most documented factors to be associated with the QoL among the enrolled thalassemia patients. The current study findings show that we need more holistic methodologies for treating thalassemia patients 
which take into consideration the emotional and social aspects of patients, the physical one. The study results also reflect our need for an educational program which train thalassemia patients to deal with the physical, emotional, and social burdens of the disease.

\section{References}

1. Baraz SH, Miladinia M, Nouri EM. A comparison of quality of life between adolescences with beta thalassemia major and their healthy peers. Int J Pediatr. 2016;4(1):1195-204.

2. Al-Gazali L, Ali B. Mutations of a country: A mutation review of single gene disorders in the United Arab Emirates (UAE). Hum Mutat. 2010;31(5):505-20. https://doi.org/10.1002/humu.21232 PMid:20437613

3. Kim S, Tridane A. Thalassemia in the United Arab Emirates: Why it can be prevented but not eradicated. PLoS One. 2017;12(1):e0170485. https://doi.org/10.1371/journal. pone.0170485

PMid:28135306

4. Rachmilewitz EA, Giardina PJ. How I treat thalassemia. Blood. 2011;118(2):3479-88.

5. Safizadeh H, Farahmandinia Z, Nejad SS, Pourdamghan N, Araste M. Quality of life in patients with thalassemia major and intermedia in Kerman-Iran (I.R.). Mediterr J Hematol Infect Dis. 2012;4(1):e2012058. https://doi.org/10.4084/mjhid.2012.058 PMid:23170187

6. Jameel T, Suliman IM, Rehman D. The compromised quality of life in $\beta$ - thalassemia major children in non-urban setup in a developing country. J Hematol Thrombo Dis. 2016;4:245. https://doi.org/10.4172/2329-8790.1000245

7. Elalfya MS, Faridb MN, Labiba JH, Allahc HK. Quality of life of Egyptian $b$ thalassemia major children and adolescents. Egypt J Haematol. 2014;39(4):222-6.

8. Goulas V, Kourakli-Symeonidis A, Camoutsis C. Comparative effects of three iron chelation therapies on the quality of life of greek patients with homozygous transfusion-dependent beta-thalassemia. Hematology. 2012;2012:139862. https://doi. org/10.5402/2012/139862

PMid:23316378

9. Gollo G, Savioli G, Balocco M, Venturino C, Boeri E, Costantini $\mathrm{M}$, et al. Changes in the quality of life of people with thalassemia major between 2001 and 2009. Patient Prefer Adherence 2013;7:231-6. https://doi.org/10.2147/ppa.s42133 PMid:23569362

10. Sheikh KA, El-Setouhy M, Yagoub U, Alsanosy R, Ahmed Z. Khat chewing and health related quality of life: Crosssectional study in Jazan region, kingdom of Saudi Arabia. Health Qual Life Outcomes. 2014;12:44. https://doi. org/10.1186/1477-7525-12-44

\section{PMid:24708622}

11. Adam S, Afifi H, Thomas M, Magdy P, El-Kamah G. Quality of Life outcomes in a pediatric thalassemia population in Egypt. Hemoglobin. 2017;41(1):16-20. https://doi.org/10.1080/036302 69.2017 .1312434
12. Musallam KM, Khoury B,Abi-Habib R, Bazzi L, Succar J, HalawiR, et al. Health-related quality of life in adults with transfusionindependent thalassaemia intermedia compared to regularly transfused thalassaemia major: New insights. Eur J Haematol. 2011;87:73-9. https://doi.org/10.1111/j.1600-0609.2011.01623.x PMid:21480999

13. Dhirar N, Khandekar J, Bachani D, Mahto D. Thalassemia Major: How do we improve quality of life? Springerplus. 2016;22(1):1895. https://doi.org/10.1186/s40064-016-3568-4 PMid:27843752

14. Adib-Hajbaghery $M$, Ahmadi M, Poormansouri S. Health related quality of life, depression, anxiety and stress in patients with beta-thalassemia major. Iran J Pediatr Hematol Oncol 2015;5(4):193-205. https://doi.org/10.1037/t67711-000 PMid:26985352

15. Dehaghi E, Rasooli LB, Farsani SM. Quality of life among patients with beta-thalassemia major in Shahrekord city, Iran. Int J Epidemiol Res 2016;3(4):324-8.

16. Hassan RH, Eldegla H, Elmorsy $F$, Eldars M. Clinical and microbiological characteristics of healthcare-associated infections in a tertiary care pediatric hospital. Egypt Pediatr Assoc Gazette. 2017;65(4):127-31. https://doi.org/10.1016/j. epag.2017.09.001

17. Forni GL, PuntoniM, Boeri E, Terenzani L, Balocco M. The influence of treatment in specialized centers on survival of patients with thalassemia major. Am J Hematol 2009;84(5):3178. https://doi.org/10.1002/ajh.21398

PMid:19396857

18. Khani H, Majdi MR, Marzabadi EA, Montazeri A, Ghorbani A, Ramezani M. Quality of life in Iranian Beta-thalassemia major patients of Southern coastwise of the Caspian Sea. JBS. 2009;4(2):325-32. https://doi.org/10.26719/2012.18.5.539

19. Ansari Sh, Baghersalimi A, Azarkeivan A, Nojomi M, Rad AH. Quality of life in patients with thalassemia major. Iran J Ped Hematol Oncol. 2014;4:57-63.

20. El Dakhakhny AM, Hesham MA, Mohamed SE, Mohammad FN. Quality of life of school age thalassemic children at Zagazig city. J Am Sci 2011;7:186-197.

21. Caocci G, Efficace F, Ciotti F, Roncarolo MG, Vacca A, Piras E, et al. Health related quality of life in Middle Eastern children with beta thalassemia. BMC Blood Disord. 2012;12(1):6. https://doi. org/10.1186/1471-2326-12-6

PMid:22726530

22. Mikelli A, Tsiantis J. Brief report. Depressive symptoms and quality of life in adolescents with b-thalassaemia. J Adolesc 2004;27(2):213-6. https://doi.org/10.1016/j. adolescence.2003.11.011 PMid: 15023520

23. Sazlina SG, Asauji YM, Juni MH. Predictors of health related quality of life among children and adolescents with beta thalassemia in three hospitals in Malaysia: A cross sectional study. Int J Public Health Clin Sci. 2015;(2):1-2.

24. Saha R, Misra R, Saha I. Health related quality of life and its predictors among Bengali Thalassemic children admitted to a tertiary care hospital. Indian J Pediatr. 2015;82(10):909-16. https://doi.org/10.1007/s12098-014-1670-6

PMid:25712005 